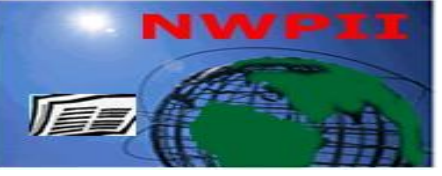

American Journal of Biomedical Sciences

ISSN: 1937-9080

nwpii.com/ajbms

\title{
Assaying Myeloperoxidase Inhibitors and Hypochlorous Acid Scavengers in HL60 Cell Line Using Quantum Dots
}

\author{
Zhongwei Liu, ${ }^{\text {a }}$ Yan Yan, ${ }^{\mathrm{a}}$ Suhua Wang, ${ }^{\mathrm{a}}$ Wei-Yi Ong, ${ }^{\mathrm{b}}$ Choon Nam Ong, ${ }^{\mathrm{c}}$ Dejian Huang ${ }^{* \mathrm{a}}$
}

${ }^{\mathrm{a}}$ Food Science and Technology Program, Department of Chemistry, National University of Singapore, 3 Science Drive 3, Singapore.

${ }^{\mathrm{b}}$ Department of Anatomy, National University of Singapore, 4 Medical Drive, Singapore.

${ }^{c}$ Department of Epidemiology and Public Health, National University of Singapore, 16 Medical Drive, Singapore.

"Corresponding author:

Food Science and Technology Programme

Department of Chemistry

National University of Singapore

3 Science Drive 3, Singapore 117543

Tel.: 65-6516-8821

Fax: 65-6775-7895

E-mail: chmhdj@nus.edu.sg

Received: 2 September 2012; | Revised: 26 February 2013; | Accepted: 29 March 2013

\begin{abstract}
A fluorescent assay for simultaneous screening of myeloperoxidase (MPO) inhibitors and hypochlorous acid ( $\mathrm{HOCl}$ ) scavengers was developed using quantum dots (QDs) as a selective HOCl probe. HL60 cells were differentiated into neutrophil phenotype and used for $\mathrm{HOCl}$ generation in this assay. The fluorescence of QDs was specifically quenched by $\mathrm{HOCl}$ generated from the neutrophil-like cells induced with phorbol 12-myristate 13-acetate (PMA) or hydrogen peroxide $\left(\mathrm{H}_{2} \mathrm{O}_{2}\right)$. Both MPO inhibitors (e.g. resveratrol) and $\mathrm{HOCl}$ scavengers (methionine and vitamin $\mathrm{C}$ ) tested in this assay could inhibit the QDs fluorescence quenching but MPO inhibitors showed a more obvious dose response relationship than $\mathrm{HOCl}$ scavengers. A microplate assay under the same conditions using 2,7-dichlorofluorescin diacetate (DCFH-DA), a commonly used reactive oxidative species (ROS) probe, was also performed to make a comparison with QDs based assay. The results indicated superior HOCl specificity of QDs over DCFH-DA and necessity of using ROS probes with different selectivity for a comprehensive evaluation of antioxidant efficiency in cellular systems. This QDs based microplate assay has a potential to be used in cell line-based high throughput screening for $\mathrm{HOCl}$ scavengers or MPO inhibitors with therapeutic importance in controlling inflammation.
\end{abstract}

Keywords: Quantum dots; Myeloperoxidase; HL60 cells; Hypochlorous acid; Inhibitor. 


\section{Introduction}

Hypochlorous acid/hypochlorite $\left(\mathrm{HOCl} / \mathrm{ClO}^{-}\right.$ ) is a powerful oxidant generated by activated neutrophils via the myeloperoxidase (MPO) catalyzed reaction of hydrogen peroxide $\left(\mathrm{H}_{2} \mathrm{O}_{2}\right)$ with chloride ions $\left(\mathrm{Cl}^{-}\right)[1,2]$. $\mathrm{HOCl}$ can promote oxidative damage and plays an important role in the pathogenesis of neurodegenerative disease $[3,4]$, atherosclerosis [5], rheumatoid arthritis [6] and other chronic inflammatory diseases $[7,8]$. Decreased MPO activity in vivo was reported to have beneficial effects in alleviating some of the pathological conditions [3,9]. Hence, $\mathrm{HOCl}$ scavenging and MPO inhibiting substances may be considered as bioactive constituents of functional foods and therapeutic agents for the prevention or treatment of the oxidative stressrelated symptoms.

There is a lack of convenient methods in quantifying MPO activity and the potency of its inhibitors. Recently, a high-affinity recombinant antibody based method was reported on rapid and sensitive direct detection of myeloperoxidase [10]. A few assays have been developed for the screening of $\mathrm{HOCl}$ scavengers and MPO inhibitors [11-15]. The mechanism behind most of these assays is the detection of chloramines, which are the $\mathrm{HOCl}$ oxidation products of proteins or amino acids. For example, Firuzi et al. [12] developed a microplate $\mathrm{HOCl}$ scavenging method based on the measurement of chloramines which oxidized 5-thio-2nitrobenzoic acid (TNB) to 5,5-dithiobis(2nitrobenzoic acid) (DTNB). Although TNB based assays are widely used for $\mathrm{HOCl}$ scavenging and MPO inhibiting assay [12,13], these assays involve complicated protocols and, more importantly, compounds such as glutathione (GSH) and N-acetylcysteine (NAC) can interfere with these assays because their reactions with DTNB or chloramines[13, 14]. In addition to TNB assay, the $\mathrm{HOCl}$ fluorescence probe aminophenyl fluorescein (APF) [16] is used in commercially available assay kit for determination of the chlorination activity of MPO in solution and cell lysates.-Most of previous assays are specifically for $\mathrm{HOCl}$ scavengers or MPO inhibitors.
The human promyelocytic leukemia HL60 cell line can be differentiated into the neutrophillike phenotype [17],which is a good model system for the generation of reactive oxidative species (ROS) induced by different agents $[13,15,18]$. In addition, the differentiated neutrophil-like cells over-express MPO and have the potential to be used in both $\mathrm{HOCl}$ scavenging and MPO inhibiting assays. Since it is important to correlate the results of in vitro assays with in vivo effects, development of a cell based method is necessary for the direct examination of $\mathrm{HOCl}$ scavengers and MPO inhibitors under physiological conditions. Although neutrophils from different sources have been used for $\mathrm{HOCl}$ generation [12-14], no reports are available on fluorescence microplate based assay using HL60 differentiated neutrophil-like cells for screening $\mathrm{HOCl}$ scavengers and MPO inhibitors simultaneously.

Quantum dots (QDs), as a novel and sensitive type of fluorescent probe for ROS. [1921] nanometer sized semiconductor crystals (quantum dots, QDs) have been used in the quick detection of both scavengers and generators of ROS. A water-soluble L-cysteine capped Mndoped CdSe@ZnS was found to enhance chemiluminescence(CL) signals emitted from interaction of $\mathrm{NaClO}$ with $\mathrm{H}_{2} \mathrm{O}_{2}$ in basic medium[22]. Nie et al. reported that the fluorescence of QDs could be quenched by $\mathrm{HOCl}$ generated from HL60 differentiated neutrophillike cells[23]. In a previous study, our lab synthesized a new type of QDs (QDs-poly- $\mathrm{CO}_{2}{ }^{-}$) for monitoring $\mathrm{HOCl}$ in tap water and MPO activity, based on the same fluorescence quenching mechanism [24]. The QDs showed good selectivity for $\mathrm{HOCl}$ over other biologically important ROS including $\mathrm{H}_{2} \mathrm{O}_{2}$, peroxynitrite $\left(\mathrm{ONOO}^{-}\right)$, superoxide $\left(\mathrm{O}_{2}{ }^{-}\right)$, and hydroxyl radical (HO'), which suggests a potential of the QDs to be applied to a cell based assay. In this study, a microplate assay for $\mathrm{HOCl}$ scavengers and MPO inhibitors was established using HL60 differentiated neutrophil-like cells combined with the HOCl-sensing QDs. Both phorbol 12myristate 13-acetate (PMA) and hydrogen peroxide were employed to induce the generation of $\mathrm{HOCl}$, which was inhibited or scavenged by 
test chemicals added to the cells. A microplate assay using the fluorescent probe 2,7dichlorofluorescin diacetate (DCFH-DA) for quantifying cellular ROS was used to make comparison with the performance of the QDs in terms of ROS selectivity.

\section{Materials and Methods}

All materials for cell culture were from GIBCO (Grand Island, NY, USA). PMA (99\%), DCFH-DA (97\%), thiourea (99\%), resveratrol (99\%), 4-aminobenzoic acid hydrazide (ABAH, 95\%), sodium azide $\left(\mathrm{NaN}_{3}, 99 \%\right)$, L-ascorbic acid (99\%), methionine (99\%), taurine (99\%) and glutathione (GSH, 98\%) were purchased from Sigma Chemical Co. (St. Louis, MO, USA). Hydrogen peroxide (30\%) was from Merck (KGaA, Darmstadt, Germany). The chemicals were dissolved in different solvents as stock solutions: DCFH-DA (10 mM), ABAH (100 $\mathrm{mM})$ in DMSO; PMA (1 mg/mL), and resveratrol $(100 \mathrm{mM})$ in ethanol; thiourea $(500 \mathrm{mM})$, taurine (200 mM), methionine (10 mM), GSH (200 mM), L-ascorbic acid $(200 \mathrm{mM})$ and $\mathrm{NaN}_{3}(1 \mathrm{M})$ in distilled water. The stock solutions of GSH and L-ascorbic acid were freshly prepared each day. Krebs-Ringers phosphate buffer (KRPB; $114 \mathrm{mM}$ $\mathrm{NaCl}, 4.6 \mathrm{mM} \mathrm{KCl}, 2.4 \mathrm{mM} \mathrm{MgSO}_{4}, 1.0 \mathrm{mM}$ $\mathrm{CaCl}_{2}, 15 \mathrm{mM} \mathrm{NaH} \mathrm{PO}_{4}, 15 \mathrm{mM} \mathrm{Na} \mathrm{HPO}_{4}, \mathrm{pH}$ 7.4) was used for dilution of the above stock solutions for the subsequent analyses. All other chemicals were of analytical grade and used directly.

\subsection{Preparation of hydrophilic QD by polymer encapsulation (QDs-Poly- $\mathrm{CO}_{2}{ }^{-}$).}

Hydrophobic $\mathrm{CdSe} / \mathrm{ZnS}$ quantum dots were synthesized according to the literature [24]. The crude QDs were purified using the precipitation method, and dissolved in dichloromethane for future use. The purified QDs had a maximum emission at $\sim 590 \mathrm{~nm}$ and the concentrations of QDs were estimated based on empirical equations as reported [24]. Poly (maleic anhydride-alt-1octadecene) $(0.050 \mathrm{~g})$ was dissolved in $\mathrm{Na}_{2} \mathrm{CO}_{3}$ (20.00 mL, 0.1 M) solution and stirred till a clear solution was obtained. Purified QDs $(5.0 \mathrm{~mL}$ in DCM) was added to the clear polymer solution and stirred overnight until a homogeneous solution was formed. The organic volatiles were removed under vacuum, and the remaining aqueous solution was centrifuged to give a clear supernatant, which was collected as the stock solution of QDs-Poly- $\mathrm{CO}_{2}{ }^{-}$and diluted in KRPB to $5 \mathrm{nM}$ for use in this study.

\subsection{Cell culture and differentiation}

HL60 cells were purchased from the American Type Culture Collection (ATCC, Manassas, VA, USA) and grown in IMDM medium supplemented with $10 \%$ fetal bovine serum, $100 \mathrm{U} / \mathrm{mL}$ penicillin, and $100 \mu \mathrm{g} / \mathrm{mL}$ streptomycin at $37{ }^{\circ} \mathrm{C}$ in a $5 \% \quad \mathrm{CO}_{2}$ humidified environment. The cells used in the assay were between 10-30 passages.

To differentiate HL60 cells into a neutrophil like phenotype, $60 \mathrm{mM}$ DMSO was added to the cell growth medium, in which the cells were cultured for 7 days. On day 7 , differentiated HL60 cells were centrifuged at $800 \mathrm{~g}$ for $5 \mathrm{~min}$ and resuspended in KRPB. Viable cells were counted on a hemocytometer using trypan blue exclusion.

\subsection{Fluorescence microplate assay}

$100 \mu \mathrm{L}$ of the cell suspension in KRPB $\left(1 \times 10^{6} / \mathrm{mL}\right)$ were added to each cell of the 96 well plate (Greiner, black wells flat bottom). The cells were incubated with $100 \mu \mathrm{L}$ of the test materials of different concentrations for $1 \mathrm{~h}$. Thereafter $20 \mu \mathrm{L}$ of QDs $(5 \mathrm{nM})$ and $20 \mu \mathrm{L}$ of PMA $(2 \mu \mathrm{g} / \mathrm{mL})$ or $\mathrm{H}_{2} \mathrm{O}_{2}(200 \mu \mathrm{M})$ were added sequentially. The microplate was shaken gently every 5 min to ensure that the cells and QDs were kept in suspension. After incubation for $30 \mathrm{~min}$, the fluorescence was measured on a microplate reader (Tecan, Infinite M200) in the top reading mode with an excitation wavelength at $400 \mathrm{~nm}$ and emission at $595 \mathrm{~nm}$. For the DCFH-DA assay, $20 \mu \mathrm{L}$ of DCFH-DA $(100 \mu \mathrm{M})$ was added in replacement of QDs and fluorescence was measured with an excitation wavelength at 485 $\mathrm{nm}$ and emission at $530 \mathrm{~nm}$.

\subsection{Data analysis}

The ability of test chemicals to scavenge or inhibit the generation of $\mathrm{HOCl}$ was measured by 
PMA or $\mathrm{H}_{2} \mathrm{O}_{2}$ treated controls in the presence or absence of the test chemicals. The inhibition rates of fluorescence quenching per well was calculated using the formula $\left[\left(\mathrm{F}_{\mathrm{t}}-\mathrm{F}_{\mathrm{p}}\right) /\left(\mathrm{F}_{\mathrm{c}^{-}}\right.\right.$ $\left.\left.\left.\mathrm{F}_{\mathrm{p}}\right)\right]^{*} 100\right]$, where $\mathrm{F}_{\mathrm{c}}=$ fluorescence without the test chemical and PMA or $\mathrm{H}_{2} \mathrm{O}_{2}, \quad \mathrm{~F}_{\mathrm{t}}=$ fluorescence with the test chemical and PMA or $\mathrm{H}_{2} \mathrm{O}_{2}$ and, $\mathrm{F}_{\mathrm{p}}=$ fluorescence with PMA or $\mathrm{H}_{2} \mathrm{O}_{2}$. The same formula was also used in the DCFHDA microplate assay to calculate the inhibition rates of fluorescence increase per well.



Figure 1. Quenching of QD fluorescence by different concentrations of neutrophil-like HL60 cells after PMA stimulation. When incubated with the same concentration of QDs and PMA for 30 min, the neutrophile like cells caused fluorescence quenching in a cell concentration-dependent manner. Pre-incubation with Resveratrol $(160 \mu \mathrm{M})$ for $1 \mathrm{~h}$ could inhibit the QD fluorescence quenching induced by PMA stimulation at all the cell concentrations. The relative fluorescence was calculated as the ratio of QD fluorescence values between the measured wells to the control well without PMA and resveratrol treatment. The error bars represent the standard deviations of four replicated wells $(\mathrm{n}=4)$

\section{Results}

The fluorescence quenching of QDs by PMA-stimulated neutrophil-like cells is shown in Figure 1. Resveratrol $(160 \mu \mathrm{M})$ was used as a MPO inhibitor [25,26] and reduced the amount of QD fluorescence quenching. Cell suspension of higher densities caused a more significant fluorescence quenching because of more $\mathrm{HOCl}$ generation. Resveratrol was found to have a maximum inhibition rate at a cell density of $1 \times 10^{6} / \mathrm{mL}$ which was adopted in this study to achieve a good sensitivity. To rule out the possibility of interaction between QDs and PMA, the QD fluorescence in KRPB without cells was investigated (Figure 2). The results show that PMA has no influence on QD fluorescence quenching. 


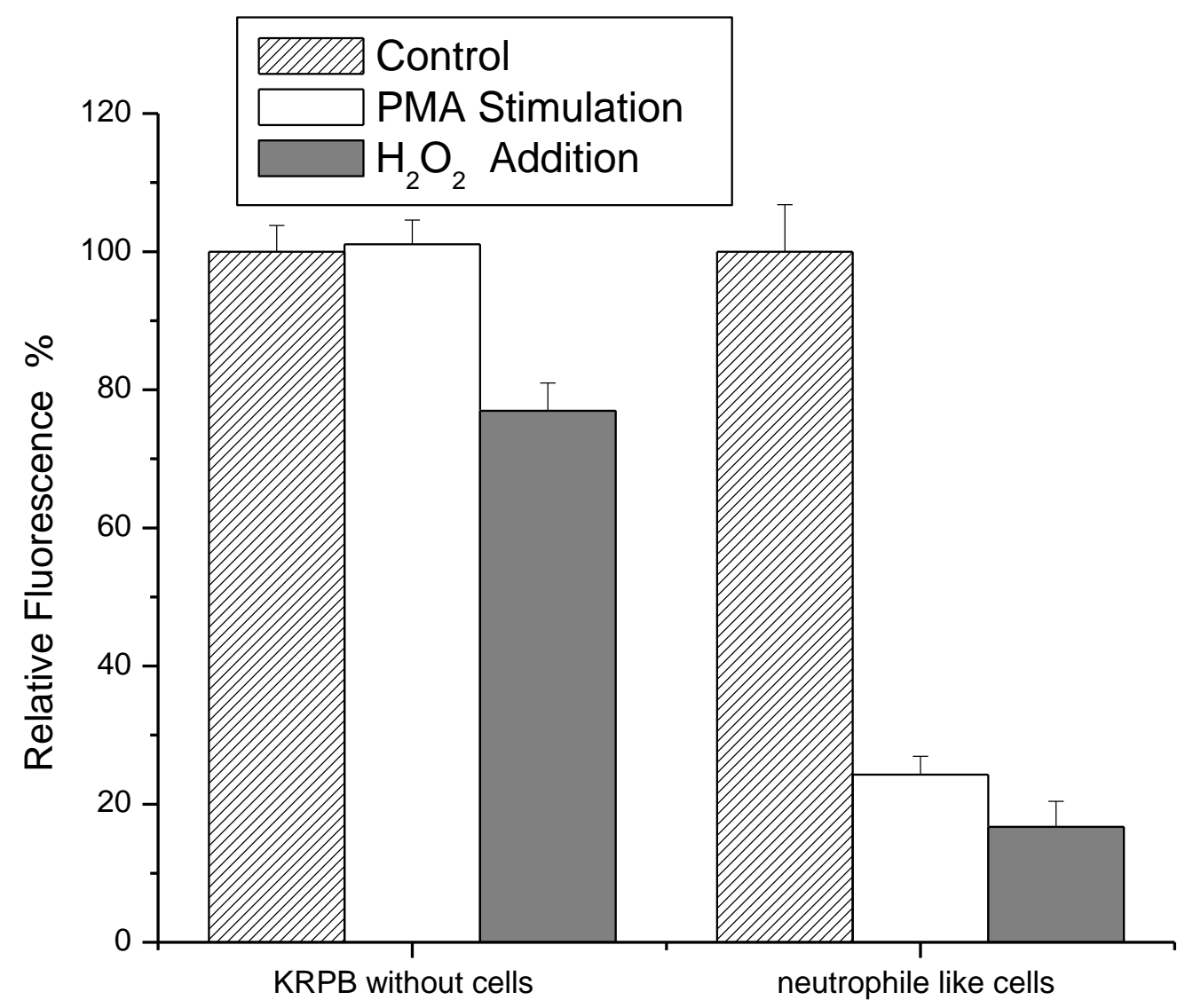

Figure 2. The influence of PMA and $\mathrm{H}_{2} \mathrm{O}_{2}$ on the QD fluorescence quenching. The PMA or $\mathrm{H}_{2} \mathrm{O}_{2}$ was incubated with neutrophil-like cells for $30 \mathrm{~min}$ after the addition of QDs. The QD fluorescence in KRPB or cell suspensions $\left(1 \times 10^{6} / \mathrm{ml}\right)$ without PMA and $\mathrm{H}_{2} \mathrm{O}_{2}$ treatment was taken as $100 \%$ of relative fluorescence. The error bars represent the standard deviations of four replicated wells $(n=4)$

The effects of test chemicals on QD fluorescence quenching inhibition is shown in Figure 3. According to their different dose response relationships, the test chemicals could be categorized into MPO inhibitors and $\mathrm{HOCl}$ scavengers. For MPO inhibitors (Figure 3A), the percentage of fluorescence quenching inhibition is correlated with the concentration in the range from $20 \mu \mathrm{M}$ to $320 \mu \mathrm{M}$ while for $\mathrm{HOCl}$ scavengers in the concentration range from 40 $\mu \mathrm{M}$ to $10 \mathrm{mM}$ (Figure 3B). The potency of MPO inhibitors tested, compared by the inhibition rate at $40 \mu \mathrm{M}$ and $320 \mu \mathrm{M}$, showed the following order: reveratrol > ABAH > sodium azide (Table 1). The inhibition rates of $\mathrm{HOCl}$ scavengers showed the order: thiourea $\approx$ methionine $>$ GSH
$>$ taurine $\approx$ L-ascorbic acid. Although both MPO inhibitors and $\mathrm{HOCl}$ scavengers dose dependently inhibited the fluorescence quenching of QDs, the concentration response relationship of MPO inhibitors is more obvious than that of $\mathrm{HOCl}$ scavengers. For example, the inhibition rate of sodium azide at $40 \mu \mathrm{M}$ is much lower than methionine and thiourea at the same concentration. However, at $320 \mu \mathrm{M}$ the inhibition rate of sodium azide is significantly higher than those of methionine and thiourea. These results have important implications for the difference between MPO inhibitors and $\mathrm{HOCl}$ scavengers in terms of HOCl-removing mechanism and

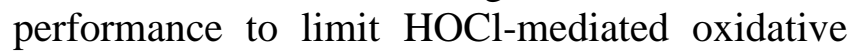
damage. 

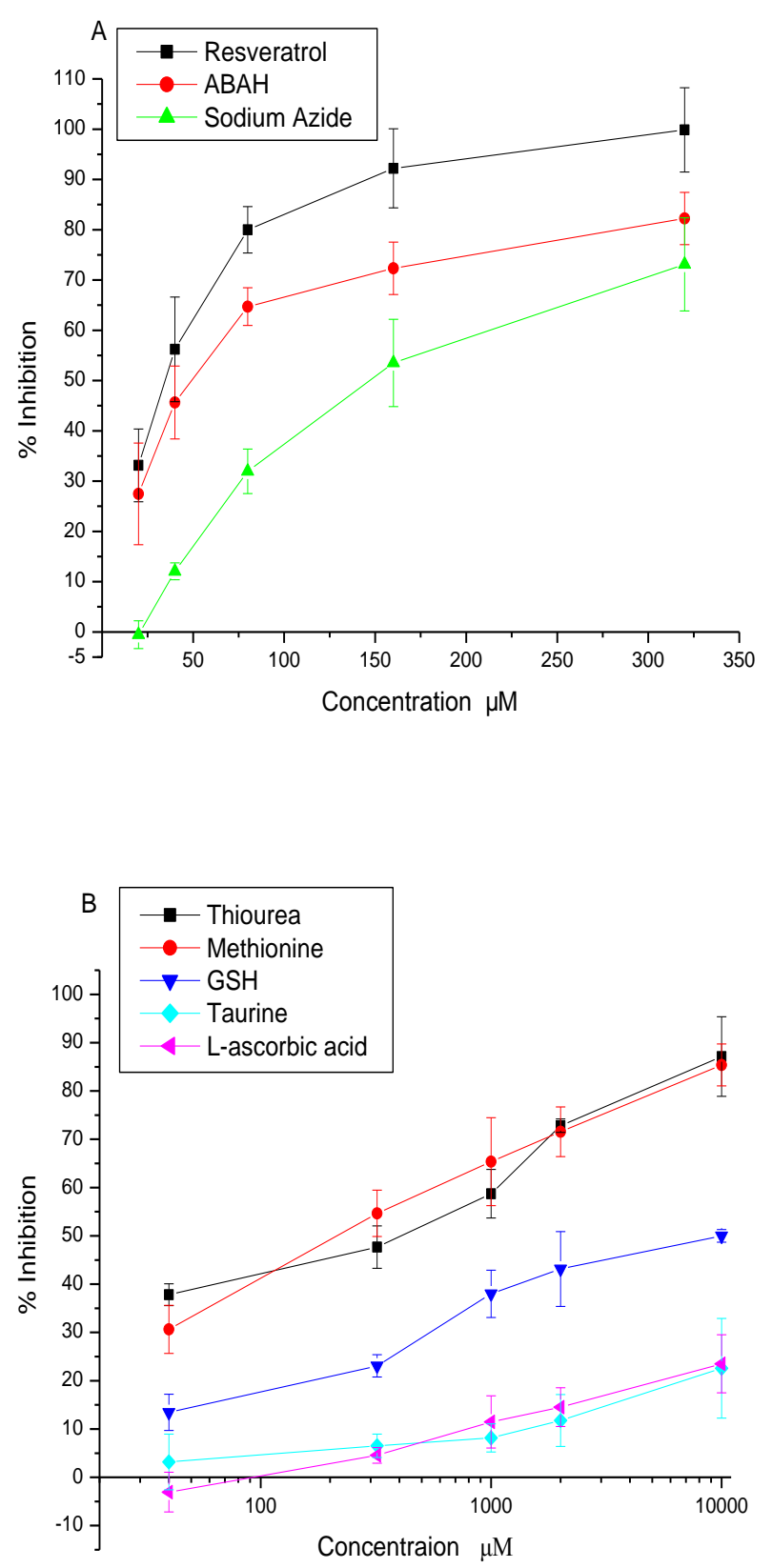

Figure 3. The dose relationship of QD fluorescence quenching inhibition by MPO inhibitors (A) and $\mathrm{HOCl}$ scavengers (B). The MPO inhibitors and $\mathrm{HOCl}$ scavengers were incubated with the neutrophil-like cells for $1 \mathrm{~h}$ before the addition of QDs and PMA. The concentration range was from $20 \mu \mathrm{M}$ to $320 \mu \mathrm{M}$ $(20 \mu \mathrm{M}, 40 \mu \mathrm{M}, 80 \mu \mathrm{M}, 160 \mu \mathrm{M}, 320 \mu \mathrm{M})$ for MPO inhibitors and from $40 \mu \mathrm{M}$ to $10 \mathrm{mM}(40 \mu \mathrm{M}, 320 \mu \mathrm{M}$, $1 \mathrm{mM}, 2 \mathrm{mM}, 10 \mathrm{mM}$ ) for $\mathrm{HOCl}$ scavengers. The error bars represent the inter-day variations of three independent assays $(n=3)$ in which the mean of data was from 4 replicated wells $(n=4)$.
Since MPO is expressed in the neutrophillike HL60 cells, $\mathrm{H}_{2} \mathrm{O}_{2}$ was added to the cells to generate $\mathrm{HOCl}$ through the $\mathrm{MPO}-\mathrm{H}_{2} \mathrm{O}_{2}-\mathrm{Cl}^{-}$ system [16]. In cell free condition the QD fluorescence was quenched by $\mathrm{H}_{2} \mathrm{O}_{2}$ to a much lesser extent than in the presence of cells which converted $\mathrm{H}_{2} \mathrm{O}_{2}$ to $\mathrm{HOCl}$ (Figure 2). The potency of MPO inhibitors, compared by the inhibition rates at $20 \mu \mathrm{M}$ and $320 \mu \mathrm{M}$, showed the order: resveratrol > ABAH > sodium azide (Table 2). For $\mathrm{HOCl}$ scavengers, the observed order is as follows: thiourea $\approx$ methionine $>\mathrm{GSH}>\mathrm{L}$ ascorbic acid > taurine. The cell permeable MPO inhibitors resveratrol and $\mathrm{ABAH}$ showed a significantly higher efficiency of quenching inhibition compared with all the $\mathrm{HOCl}$ scavengers, which is consistent with the results from the PMA stimulated cells. The test chemicals at a concentration of $320 \mu \mathrm{M}$ were also shown to have no significant influence on the QD fluorescence in the absence of cells (Figure 4).

The time course of QDs quenching due to PMA stimulation and $\mathrm{H}_{2} \mathrm{O}_{2}$ addition to the neutrophil-like cells was also investigated. Figure 5 shows that the $\mathrm{H}_{2} \mathrm{O}_{2}$ QD fluorescence quenching reaction went to completion within 10 minutes whereas PMA stimulation caused a gradual quenching process extending over 30 minutes. The results indicate different mechanisms of $\mathrm{HOCl}$ generation by $\mathrm{H}_{2} \mathrm{O}_{2}$ and PMA. The addition of $\mathrm{H}_{2} \mathrm{O}_{2}$ quenched the QD fluorescence faster than the PMA stimulation because $\mathrm{H}_{2} \mathrm{O}_{2}$ is directly used as a substrate by MPO to generate $\mathrm{HOCl}$ whereas after PMA addition, the amount of $\mathrm{HOCl}$ is limited by the generation of $\mathrm{H}_{2} \mathrm{O}_{2}$ which needs activation of NADPH oxidase and superoxide dismutase.

Finally, a microplate assay using another ROS fluorescent probe DCFH-DA was conducted to evaluate all the test chemicals in the QD based microplate assay. Table 3 shows that only GSH and L-ascorbic acid $(320 \mu \mathrm{M})$ significantly inhibited the ROS induced fluorescence increase in $\mathrm{H}_{2} \mathrm{O}_{2}$ and PMA stimulated cells. This result is in stark contrast to the inhibition order of the tested chemicals from the QD based microplate assay, which indicated the different selectivity of the two fluorescent probes for ROS generated by the cells. Also, the effect of $\mathrm{H}_{2} \mathrm{O}_{2}$ and PMA on 
the DCFH-DA fluorescence in KRPB without influence was found (Figure 6). cells was investigated and no significant

Table 1. Comparison of the potency of MPO inhibitors and $\mathrm{HOCl}$ scavengers in inhibiting the QD fluorescence quenching induced by PMA stimulation

\begin{tabular}{|c|c|c|c|c|c|c|}
\hline Compounds & $\begin{array}{c}\text { Inhibition } \\
(\text { mean } \pm \text { S.D.\%) at } \\
40 \mu \mathrm{M}\end{array}$ & $\begin{array}{c}\text { Inter-day variation } \\
\text { (R.S.D.\%,n=3) }\end{array}$ & $\begin{array}{c}\text { Intra-day } \\
\text { variation } \\
\text { (R.S.D.\%,n=4) }\end{array}$ & $\begin{array}{c}\text { Inhibition } \\
(\text { mean } \pm \text { S.D.\%) at } \\
320 \mu \mathrm{M}\end{array}$ & $\begin{array}{c}\text { Inter-day variation } \\
\text { (R.S.D.\%,n=3) }\end{array}$ & $\begin{array}{c}\text { Intra-day } \\
\text { variation } \\
\text { (R.S.D.\%,n=4) }\end{array}$ \\
\hline \multicolumn{7}{|l|}{ MPO inhibitors } \\
\hline Resveratrol & $56.21 \pm 10.40$ & 18.50 & 2.66 & $99.86 \pm 8.37$ & 8.38 & 3.50 \\
\hline $\mathrm{ABAH}$ & $45.24 \pm 7.25$ & 16.03 & 6.47 & $82.24 \pm 5.20$ & 6.32 & 6.07 \\
\hline Sodium Azide & $12.50 \pm 1.68$ & 13.44 & 7.14 & $73.10 \pm 9.26$ & 12.67 & 7.23 \\
\hline \multicolumn{7}{|l|}{$\mathrm{HOCl}$ scavengers } \\
\hline Thiourea & $37.80 \pm 2.26$ & 5.98 & 17.11 & $47.66 \pm 4.39$ & 9.21 & 15.81 \\
\hline Methionine & $30.65 \pm 4.98$ & 16.25 & 11.74 & $54.65 \pm 4.80$ & 8.78 & 7.46 \\
\hline GSH & $13.45 \pm 3.76$ & 27.96 & 20.20 & $23.08 \pm 2.32$ & 9.95 & 13.75 \\
\hline Taurine & - & - & - & $6.53 \pm 2.43$ & 37.21 & 44.08 \\
\hline L-ascorbic Acid & - & - & - & $4.55 \pm 1.62$ & 35.60 & 41.14 \\
\hline
\end{tabular}

-, No inhibition effect.

Table 2 Comparison of the potency of MPO inhibitors and $\mathrm{HOCl}$ scavengers in inhibiting the QD fluorescence quenching induced by $\mathrm{H}_{2} \mathrm{O}_{2}$ addition

\begin{tabular}{|c|c|c|c|c|c|c|}
\hline Compounds & $\begin{array}{c}\text { Inhibition } \\
(\text { mean } \pm \text { S.D. \%) at } \\
20 \mu \mathrm{M}\end{array}$ & $\begin{array}{c}\text { Inter-day variation } \\
\text { (R.S.D.\%,n=3) }\end{array}$ & $\begin{array}{c}\text { Intra-day } \\
\text { variation } \\
\text { (R.S.D.\%,n=4) }\end{array}$ & $\begin{array}{c}\text { Inhibition } \\
(\text { mean } \pm \text { S.D. \%) at } \\
320 \mu \mathrm{M}\end{array}$ & $\begin{array}{c}\text { Inter-day variation } \\
\text { (R.S.D.\%,n=3) }\end{array}$ & $\begin{array}{c}\text { Intra-day } \\
\text { variation } \\
\text { (R.S.D.\%,n=4) }\end{array}$ \\
\hline
\end{tabular}

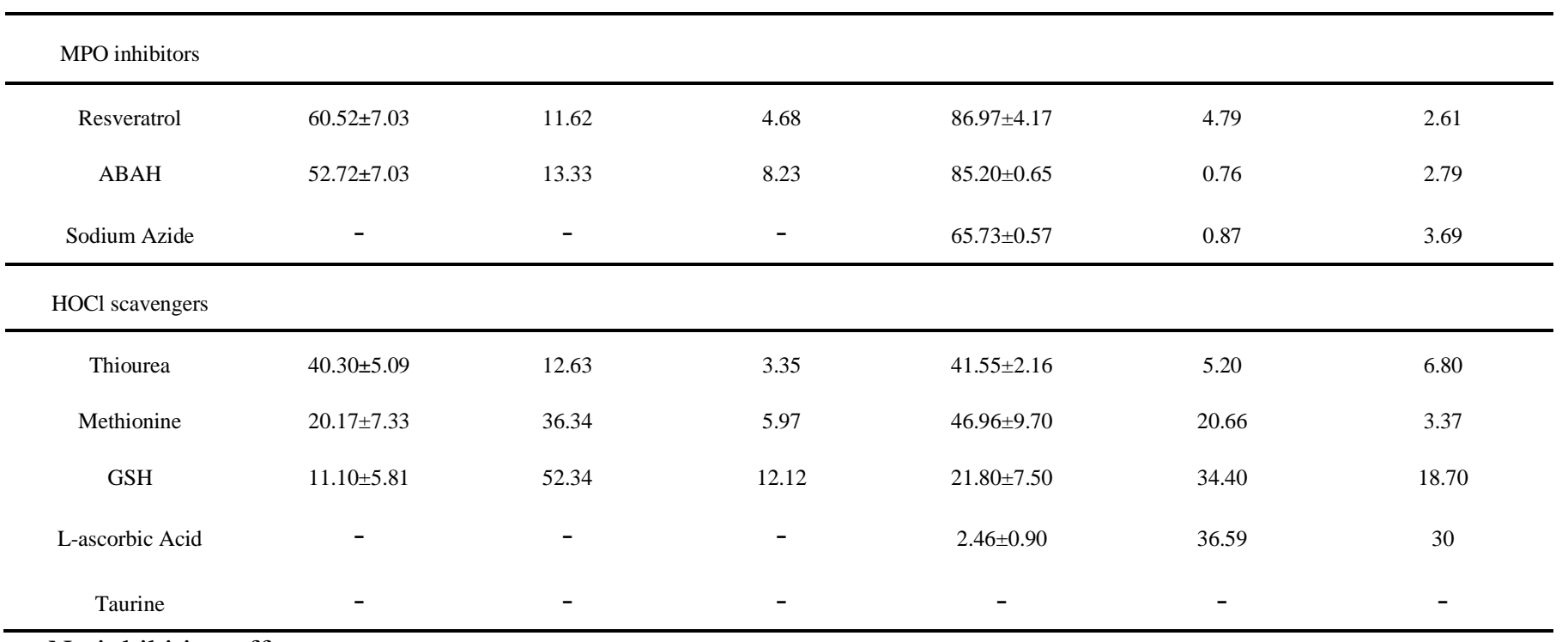

-, No inhibition effect. 
Table 3 Comparison of the potency of MPO inhibitors and $\mathrm{HOCl}$ scavengers in inhibiting the DCFH-DA fluorescence increase induced by PMA stimulation and $\mathrm{H}_{2} \mathrm{O}_{2}$ addition

\begin{tabular}{|c|c|c|c|c|c|c|}
\hline \multirow[b]{2}{*}{ Compounds } & \multicolumn{3}{|c|}{ PMA stimulation } & \multicolumn{3}{|c|}{$\mathrm{H}_{2} \mathrm{O}_{2}$ addition } \\
\hline & $\begin{array}{c}\text { Inhibition } \\
(\text { mean } \pm \text { S.D. } \%) \text { at } \\
320 \mu \mathrm{M} \\
\end{array}$ & $\begin{array}{c}\text { Inter-day variation } \\
\text { (R.S.D.\%,n=3) }\end{array}$ & $\begin{array}{c}\text { Intra-day } \\
\text { variation } \\
\text { (R.S.D.\%,n=4) }\end{array}$ & $\begin{array}{c}\text { Inhibition } \\
(\text { mean } \pm \text { S.D. \%) at } \\
320 \mu \mathrm{M} \\
\end{array}$ & $\begin{array}{l}\text { Inter-day variation } \\
\text { (R.S.D.\%,n=3) }\end{array}$ & $\begin{array}{c}\text { Intra-day } \\
\text { variation } \\
\text { (R.S.D. } \%, \mathrm{n}=4 \text { ) }\end{array}$ \\
\hline \multicolumn{7}{|l|}{ MPO inhibitors } \\
\hline Resveratrol & - & - & - & - & - & - \\
\hline $\mathrm{ABAH}$ & $24.35 \pm 3.32$ & 13.63 & 5.04 & - & - & - \\
\hline Sodium Azide & - & - & - & - & - & - \\
\hline \multicolumn{7}{|l|}{$\mathrm{HOCl}$ scavengers } \\
\hline L-ascorbic Acid & $52.29 \pm 3.31$ & 6.33 & 17.25 & $17.25 \pm 7.32$ & 42.43 & 14.32 \\
\hline GSH & $31.74 \pm 6.00$ & 18.90 & 13.27 & $29.49 \pm 0.74$ & 2.51 & 4.17 \\
\hline Methionine & $14.50 \pm 7.85$ & 54.14 & 6.86 & $17.86 \pm 3.24$ & 18.14 & 5.84 \\
\hline Taurine & - & - & - & - & - & - \\
\hline Thiourea & - & - & - & - & - & - \\
\hline
\end{tabular}

-, No inhibition effect.

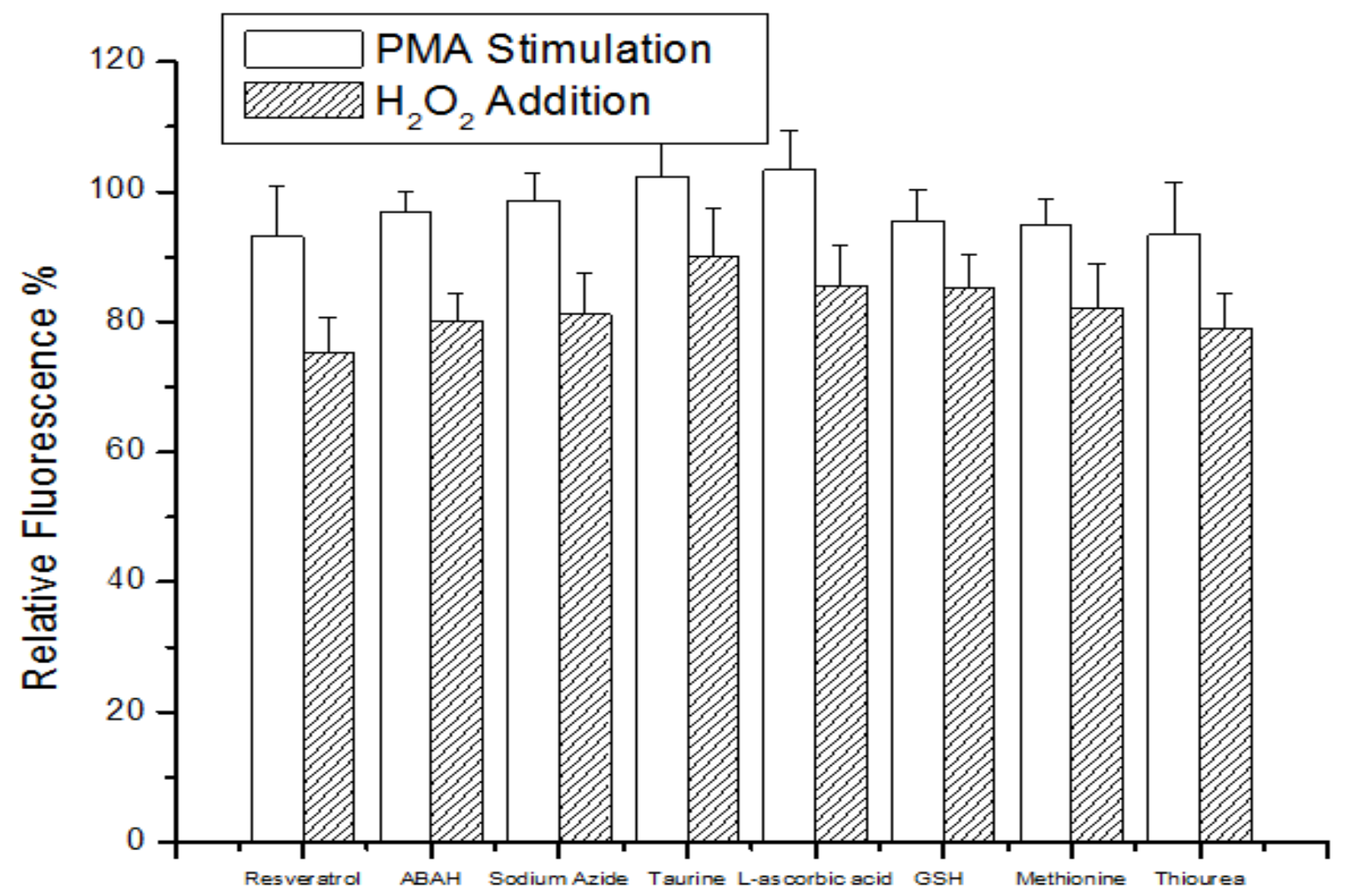

Figure 4. The influence of the test chemicals on the QD fluorescence quenching. The test chemicals at a concentration of $320 \mu \mathrm{M}$ were incubated with PMA or $\mathrm{H}_{2} \mathrm{O}_{2}$ for 30 min after the addition of QDs. The QD fluorescence in KRPB without any treatment was taken as $100 \%$ of relative fluorescence. The error bars represent the standard deviations of four replicated wells $(n=4)$. 


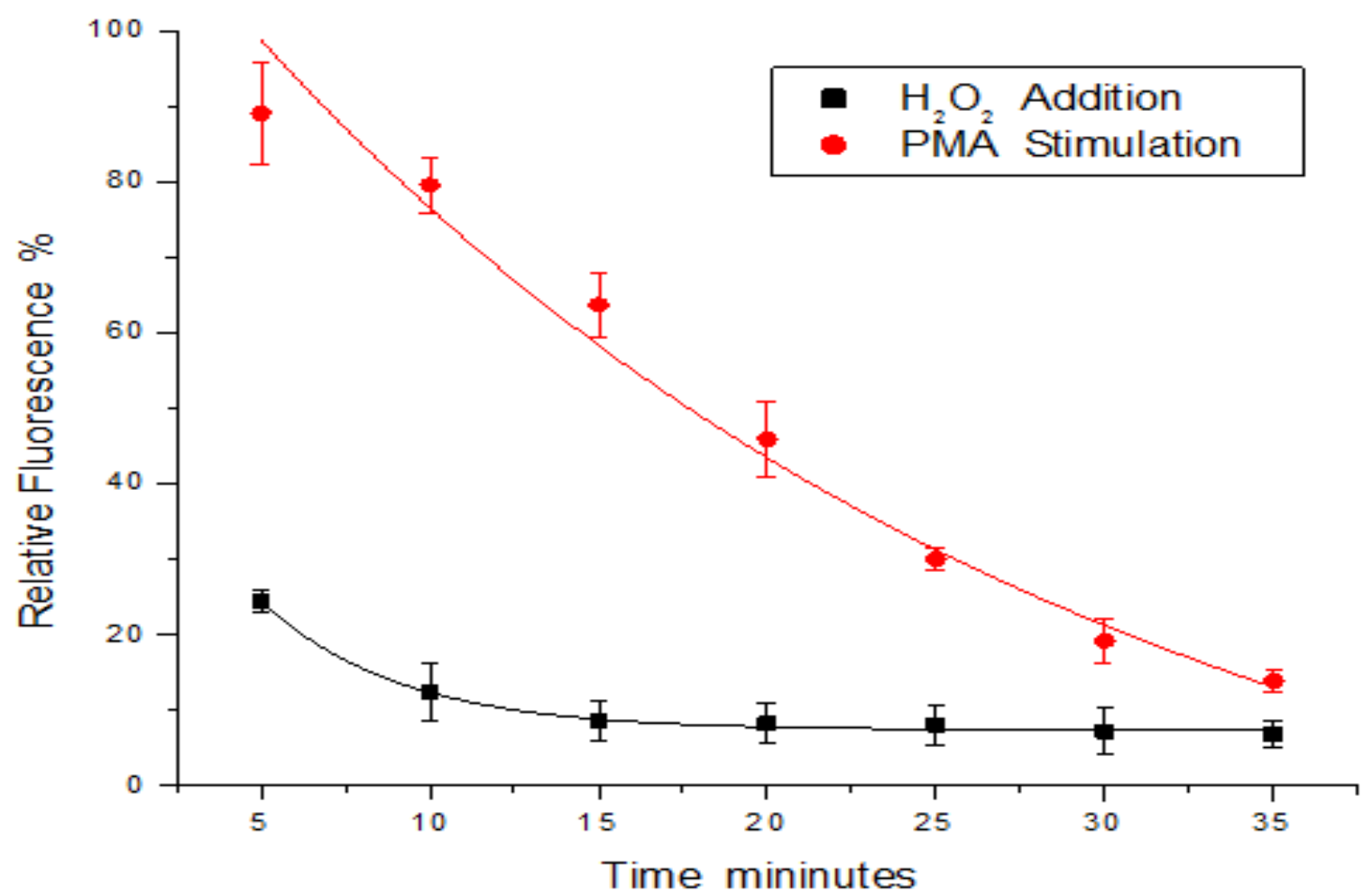

Figure 5. The time course curve of QD fluorescence quenching by neutrophil-like cells after PMA stimulation or $\mathrm{H}_{2} \mathrm{O}_{2}$ addition. The relative fluorescence was calculated as formula: $\left.\left[\left(\mathrm{F}_{\mathrm{p}}-\mathrm{F}_{\mathrm{b}}\right) /\left(\mathrm{F}_{\mathrm{c}}-\mathrm{F}_{\mathrm{b}}\right)\right]^{*} 100\right]$, where $\mathrm{F}_{\mathrm{p}}=\mathrm{QD}$ fluorescence with PMA or $\mathrm{H}_{2} \mathrm{O}_{2}$ treatment, $\mathrm{F}_{\mathrm{b}}=$ background fluorescence without QDs, $\mathrm{F}_{\mathrm{c}}=$ QD fluorescence without PMA or $\mathrm{H}_{2} \mathrm{O}_{2}$ treatment. All the three fluorescence parameters were measured every 5 minutes. The error bars represent the standard deviations of four replicated wells $(n=4)$.

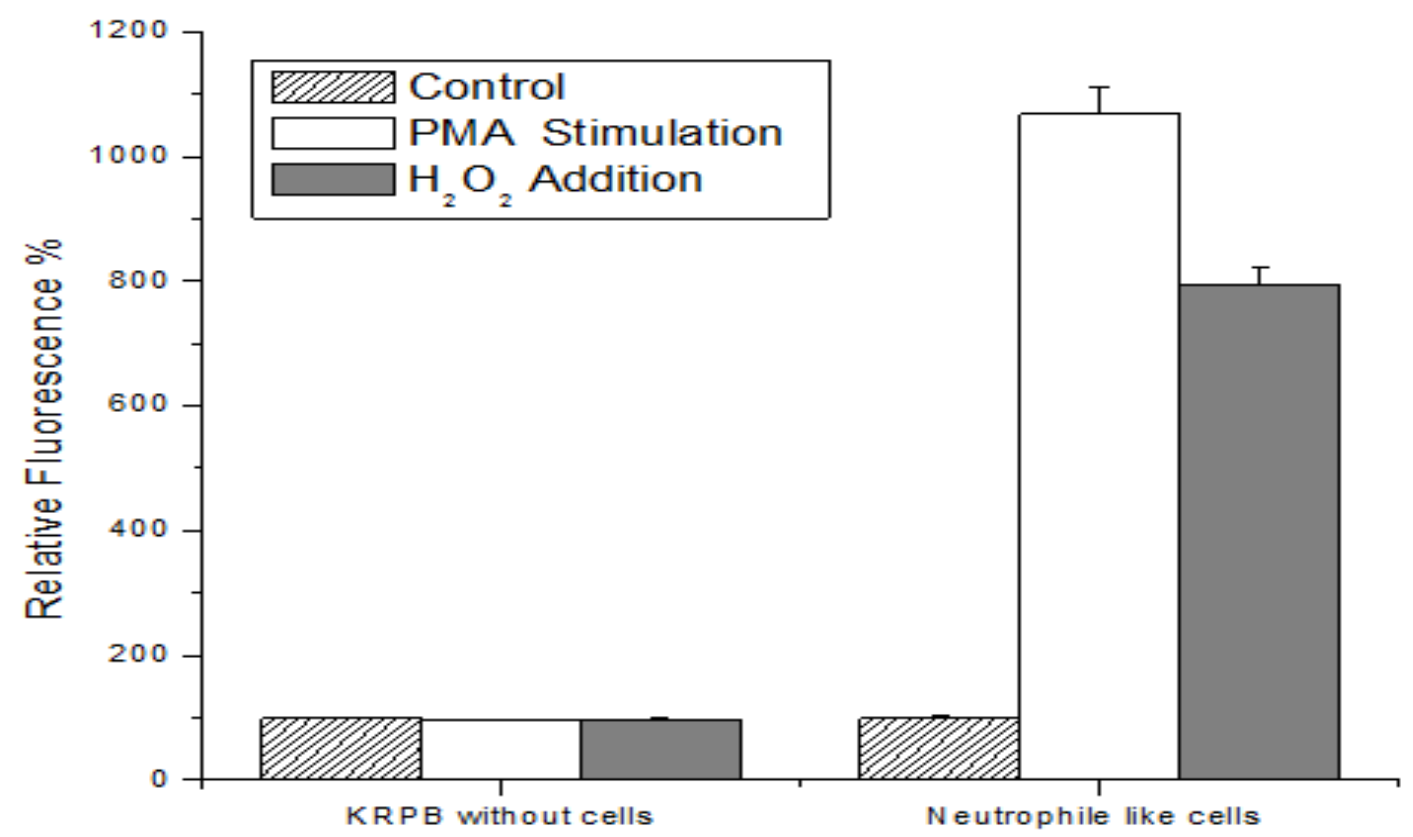

Figure 6. The influence of PMA stimulation and $\mathrm{H}_{2} \mathrm{O}_{2}$ addition on the DCFH-DA fluorescence increase. The PMA or $\mathrm{H}_{2} \mathrm{O}_{2}$ was incubated with neutrophil-like cells for 30 minutes after the addition of DCFH-DA. The DCFH-DA fluorescence in KRPB or cell suspensions $\left(1 \times 10^{6} / \mathrm{ml}\right)$ without PMA and $\mathrm{H}_{2} \mathrm{O}_{2}$ treatment was taken as $100 \%$ of relative fluorescence. The error bars represent the standard deviations of four replicated wells $(n=4)$. 


\section{Discussion}

The specificity of $\mathrm{HOCl}$ detection over other biologically important ROS by QDs has been demonstrated in the former study showing that only $\mathrm{HOCl}$ rapidly quenched the fluorescence of QDs within $10 \mathrm{~min}$ [24]. The high selectivity of QD quenching by $\mathrm{HOCl}$ could be attributed to the diffusion of electronically neutral $\mathrm{HOCl}$ across the negative layer of QD surface polymer coatings while other ROS are difficult to penetrate the polymer layer due to their negative charges or very short life time. Although $\mathrm{H}_{2} \mathrm{O}_{2}$ is stable and neutral, it is not a strong oxidant as $\mathrm{HOCl}$ which can cause QD surface etching and subsequent fluorescence quenching. Compared with the former study, [24] the QD fluorescence was quenched to a greater extent by $\mathrm{H}_{2} \mathrm{O}_{2}$ in this study due to lower concentration of QDs and higher concentration of $\mathrm{H}_{2} \mathrm{O}_{2}$ added. In this study the amount of $\mathrm{HOCl}$ produced by HL60 cells was not quantified because the $\mathrm{HOCl}$ spiked standard curve cannot be used for determining the amount of $\mathrm{HOCl}$ which is generated by HL60 cells in a gradual process over time. Instead, the assay provide a relative measurement of MPO activity in generating $\mathrm{HOCl}$.

The present study was carried out to evaluate the use of QDs in a microplate based assay to detect MPO inhibition or $\mathrm{HOCl}$ scavenging. MPO inhibitors showed a more obvious concentration response relationship than $\mathrm{HOCl}$ scavengers. This could be explained by different $\mathrm{HOCl}$ removal mechanisms. $\mathrm{HOCl}$ scavengers could not block the generation of $\mathrm{HOCl}$ but inhibited QD fluorescence quenching through a competition mechanism. Therefore, a significantly higher concentration of $\mathrm{HOCl}$ scavengers was required to reach an inhibition rate over $70 \%$ when compared with MPO inhibitors. Jerlich et al.[27] also reported that higher concentrations of $\mathrm{HOCl}$ scavengers than MPO inhibitors were required for the prevention of low density lipoprotein (LDL) oxidation by the $\mathrm{MPO} / \mathrm{H}_{2} \mathrm{O}_{2} / \mathrm{Cl}^{-}$system, which indicates that MPO inhibitors are more efficient in reducing $\mathrm{HOCl}$ than $\mathrm{HOCl}$ scavengers.

Previous study [28] has demonstrated that $\mathrm{HOCl}$ reacts readily with many biological molecules, particularly those with organosulfides and amino groups such as methionine and GSH. Given the rapid reaction rates of $\mathrm{HOCl}$ with biological materials, high doses of conventional antioxidants such as Lascorbic acid and thiols are required to effectively protect against direct oxidative damage by $\mathrm{HOCl}$ [29]. Other biological ROS such as $\mathrm{ONOO}^{-}$and $\mathrm{HO}$ may also compete with $\mathrm{HOCl}$ for antioxidants. In addition, antioxidants such as taurine can react with $\mathrm{HOCl}$ and generate chloramines (RNHCl) which are reactive oxidants and key intermediates in $\mathrm{HOCl}-$ mediated damage [30]. Therefore, inhibiting the generation of $\mathrm{HOCl}$ may be a better choice than scavenging $\mathrm{HOCl}$ after its generation, for amelioration of $\mathrm{HOCl}$ induced biological damage.

Resveratrol, the most potent MPO inhibitor found in this study, has been reported to significantly decrease $\mathrm{HOCl}$ production in human and equine neutrophils $[25,26]$. In contrast to synthetic MPO inhibitors such $\mathrm{ABAH}$ and $\mathrm{NaN}_{3}$, resveratrol is a phytochemical from grape skins and other plant sources, implying a great potential of screening and identification of potent MPO inhibitors from natural products. Resveratrol also showed a $\mathrm{HOCl}$ scavenging potency comparable to L-ascorbic acid [31]. However, in this study resveratrol had much higher fluorescence quenching inhibition efficiency than L-ascorbic acid, which indicates that resveratrol mainly functions as a MPO inhibitor to reduce the $\mathrm{HOCl}$ production by neutrophil-like cells. Since previous study showed that even a small dose of resveratrol $(4.38 \mathrm{nM})$ attainable by the alimentary route could effectively inhibited $\mathrm{HOCl}$ generation in human neutrophils, resveratrol could act as a reference compound to evaluate the performance of other MPO inhibitors and $\mathrm{HOCl}$ scavengers in vivo. Compared with previous study [25,26], a significantly higher concentration of resveratrol in this study was required to completely inhibit fluorescence quenching, which might be due to the very low concentration of QDs applied in the assay and the fast reaction rate of QDs with $\mathrm{HOCl}$ demonstrated in our previous study [24]. 
PMA and $\mathrm{H}_{2} \mathrm{O}_{2}$ were used to induce $\mathrm{HOCl}$ generation by HL60 neutrophil-like cells. Unlike the neutrophils isolated from whole blood, the commercially available HL60 cells are not limited by availability of blood samples, and hence more suitable for the large-scale screening assay. Compared with other adherent cell types, non-adherent neutrophil-like cells used in the microplate assay also have the advantages including no need for pre-seeding and thus reduced variability of the assay due to the variable cell numbers. Most importantly, myeloid derived HL60 cells over-express MPO and could be induced to produce a much higher level of $\mathrm{HOCl}$ than other cell lines.

Neutrophil-like cells stimulated by PMA undergo a "respiratory burst", which leads to extracellular release of MPO and $\mathrm{HOCl}$. Although PMA stimulation is a classic method for $\mathrm{HOCl}$ generation in neutrophil-like cells, the selectivity of the assay may be compromised by other "respiratory burst" relevant enzymes inhibitors such as NADPH oxidase inhibitor diphenyliodonium (DPI) which also blocks $\mathrm{HOCl}$ generation, as demonstrated in the previous study[17]. To overcome this disadvantage, the cells were directly exposed to $\mathrm{H}_{2} \mathrm{O}_{2}$ which could is the substrate in generating $\mathrm{HOCl}$ by oxidation of Cl- mediated by MPO. Burns et al. [18] reported a fast conversion of $\mathrm{H}_{2} \mathrm{O}_{2}$ to $\mathrm{HOCl}$ by HL60 cells within minutes. To avoid inhibition of MPO, the $\mathrm{H}_{2} \mathrm{O}_{2}$ concentration employed in the assay was kept below $20 \mu \mathrm{M}$, as recommended by Kettle et al. [8] Although in HL60 cells the mechanisms of $\mathrm{HOCl}$ generation by PMA stimulation and $\mathrm{H}_{2} \mathrm{O}_{2}$ addition were different, the similar potency orders of $\mathrm{HOCl}$ scavengers and MPO inhibitors shown by the two methods indicated the selectivity of QDs for $\mathrm{HOCl}$. This is in contrast with the different potency orders observed in the DCFH-DA microplate assay which might be due to different ROS generated by PMA stimulation and $\mathrm{H}_{2} \mathrm{O}_{2}$ addition.

The inhibition efficiency of $\mathrm{HOCl}$ scavengers shown in this study was basically consistent with the order of relative reaction rates reported by Winterbourn [29] in which organosulfide compounds (methionine and GSH) were much more reactive than $\mathrm{L}$-ascorbic acid and taurine. Although there was no literature for comparing the potency of MPO inhibitors tested in this study, resveratrol was reported to be more efficient in blocking MPO-triggered formation of DNA-centered radicals than ABAH [29] the analog of which pHBAH was demonstrated to be much more effective in preventing MPO induced LDL oxidation than sodium azide. These indirect comparisons from previous studies correlated well with the potency order of MPO inhibitors given in this study. Since the inhibition rates in this cell based assay did not show a linear dose response relationship and the inhibition rates of some $\mathrm{HOCl}$ scavengers did not reach $50 \%$ even at a concentration of $10 \mathrm{mM}, \mathrm{IC}_{50}$ values were not adopted as indicators for $\mathrm{HOCl}$ inhibition efficiency. However, this does not impair the performance of this cell based assay for the identification of the most effective $\mathrm{HOCl}$ inhibitor such as resveratrol which could be achieved through comparing the potency order at the concentration of $320 \mu \mathrm{M}$.

Another difference between PMA stimulation and $\mathrm{H}_{2} \mathrm{O}_{2}$ addition to generate $\mathrm{HOCl}$ is that PMA caused neutrophil degranulation leading to extracellular MPO and $\mathrm{HOCl}$ release, whereas the added $\mathrm{H}_{2} \mathrm{O}_{2}$ is mainly converted by intracellular MPO to $\mathrm{HOCl}$ which diffuses outside the cells. The addition of $\mathrm{H}_{2} \mathrm{O}_{2}$ may therefore be more suitable for evaluation of intracellular MPO inhibitors. Unlike organic fluorescent probes, QDs have poor cell permeability and could not enter the cell in a diffusible way especially in such a short time as 30 minutes. This could provide QDs with another advantage, in that the quenching of QDs fluorescence would not be influenced by the complex intracellular environment containing other interfering peroxidase [14,17]. So there is no need for extraction and purification of MPO from neutrophils or the whole blood cells [13], which makes the QDs based microplate assay less time-consuming and laborious compared with previous methods.

Finally, a microplate assay using DCFH-DA under the same condition was conducted to make a comparison with the performance of QDs. DCFH-DA is an organic fluorescent probe widely used for quantification of cellular oxidative stress 
and assessment of antioxidant effects [32]. Lascorbic acid (Vitamin C) in this assay exhibited a strong antioxidant efficacy, which is consistent with the result of a previous assay based on the same principle [33]. However, in the same assay, all the MPO inhibitors showed weak or no inhibition effects for ROS-induced fluorescence increase, and similar results were observed for methionine and thiourea which are known to be highly efficient $\mathrm{HOCl}$ scavengers. The reason for the contrast between QDs and DCFH-DA based microplate assays might be different selectivity of two fluorescent probes for ROS because DCFHDA is a non-specific ROS probe and its intracellular hydrolysis product 2,7dichlorofluorescin (DCFH) was reported to have a low reactivity with $\mathrm{HOCl}[16]$. Myhre et al. [34] critically assessed the different ROS identified by the DCFH-DA assay and also suggested that DCFH could measure $\mathrm{ONOO}^{-},{ }^{\circ} \mathrm{OH}$, and $\mathrm{H}_{2} \mathrm{O}_{2}$ in the presence of cellular peroxidases but was not suitable for detection of $\mathrm{HOCl}, \mathrm{NO}$, or $\mathrm{O}_{2}{ }^{-{ }^{-}}$in biological systems. Therefore, a combined use of ROS probes with different selectivity should be necessary for a comprehensive evaluation of antioxidant efficiency in a cell based assay.

In summary, a simple, fast cell based microplate assay was developed for the screening of highly efficient $\mathrm{HOCl}$ scavengers and MPO inhibitors which can be distinguished by their different dose response relationships. The MPO inhibitors exhibited a significantly higher efficiency for QD fluorescence quenching inhibition than the $\mathrm{HOCl}$ scavengers, which indicates more potential of MPO inhibitors as effective $\mathrm{HOCl}$ removers. Comparison between DCFH-DA and QDs demonstrates the importance of using more ROS probes with different selectivity for a comprehensive antioxidant evaluation especially when cells were used as ROS generation sources.

\section{Acknowledgements}

The authors are grateful for the financial support of the Science and Engineering Research Council (SERC) of the Agency for Science, Technology and Research (A*Star) of Singapore. Grant Number: 072-101-0015.

\section{Abbreviations Used}

QDs, quantum dots; MPO, myeloperoxidase; TNB, 5-thio-2-nitrobenzoic acid; DTNB, 5,5dithiobis(2-nitrobenzoic acid); GSH, glutathione; APF, aminophenyl fluorescein; PMA, Phorbol 12-myristate 13-acetate; DCFH-DA, 2,7dichlorofluorescin diacetate; ROS, reactive oxidative species; $\mathrm{HO}^{*}$, hydroxyl radical; $\mathrm{HOCl}$, hypochlorous acid; $\mathrm{H}_{2} \mathrm{O}_{2}$, hydrogen peroxide; ABAH, 4-aminobenzoic acid hydrazide; ONOO', peroxynitrite; $\mathrm{O}_{2}{ }^{\cdot-}$, superoxide.

\section{References}

1. AKettle, A. J., Neutrophils convert tyrosyl residues in albumin to chlorotyrosine, FEBS Lett., 1996, 379,103-106. DOI: 10.1016/0014-5793(95)01494-2

2. Stankovic, S.; Majkic-Singh, N., Myeloperoxidase: new roles for an old molecule, J. Med. Biochem., 2011, 30, 230236. DOI: $10.2478 / v 10011-011-0033-3$

3. Maki, R. A.; Tyurin, V. A.; Lyon, R. C.; Hamilton, R. L.; Dekosky, S. T.; Kagan, V. E.; Reynold, W. F. Aberrant expression of myeloperoxidase in astrocytes promotes phospholipid oxidation and memory deficits in a mouse model of Alzheimer disease, J. Biol. Chem., 2009, 284, 3158-3169. DOI: 10.1074/jbc.M807731200

4. Choi, D. K.; Pennathur, S.; Perier, C.; Tieu, K.; Teismann, P.; Wu, D. C.; JacksonLewis, V.; Vila, M.; Vonsattel, J. P.; Heinecke, J. W.; Przedborski, S., Ablation of the inflammatory enzyme myeloperoxidase mitigates features of Parkinson's disease in mice, J. Neurosci., 2005, 25, 6594-6600. DOI: 10.1523/JNEUROSCI.0970-05.2005

5. Heinecke, J. W. Mechanisms of oxidative damage by myeloperoxidase in atherosclerosis and other inflammatory disorders, J. Lab. Clin. Med. 1999, 133, 321-325. DOI: 10.1016/S00222143(99)90061-6

6. Babior, B. M. Phagocytes and oxidative stress, Am. J. Med., 2000, 109, 33-44. DOI: $\underline{10.1016 / \mathrm{S} 0002-9343(00) 00481-2}$ 
7. Blackburn, A. C.; Doe, W. F.; Buffinton, G. D., Protein carbonyl formation on mucosal proteins in vitro and in dextran sulfate induced colitis, Free Radical Biol. Med., 1999, 27, 262-270. DOI: 10.1016/S08915849(99)00065-9

8. Kettle, A. J.; Chan, T.; Osberg, I.; Senthilmohan, R.; Chapman, A. L. P.; Mocatta, T. J.; Wagener, J. S. Myeloperoxidase and protein oxidation in the airways of young children with cystic fibrosis. Am. J. Respir. Crit. Care Med., 2004, 170, 1317- 1323. DOI: 10.1164/rccm.200311-1516OC

9. Kutter, D.; Devaquet, P.; Vanderstocken, G.; Paulus, J. M.; Marchal, V.; Gothot, A.; Consequences of total and subtotal myeloperoxidase deficiency: risk or benefit? Acta Haematol., 2000, 104, 10-15. DOI: $\underline{10.1159 / 000041062}$

10. McDonnell, B.; Hearty, S.; Finlay, W. J. J.; O'Kennedy, R., A high-affinity recombinant antibody permits rapid and sensitive direct detection of myeloperoxidase, Anal. Biochem., 2011, 410, 1-6. DOI: 10.1016/j.ab.2010.09.039

11. Yan, L. J.; Traber, M. G.; Kobuchi, H.; Matsugo, S.; Tritschler, H. J.; Packer, L., Efficacy of hypochlorous acid scavengers in the prevention of protein carbonyl formation, Arch. Biochem. Biophys., 1996, 327, 330334. DOI: 10.1006/abbi.1996.0130.

12. Firuzi, O.; Giansanti, L.; Vento, R.; Seibert, C.; Petrucci, R.; Marrosu, G.; Agostino, G.; Saso, L., Hypochlorite scavenging activity of hydroxycinnamic acids evaluated by a rapid microplate method based on the measurement of chloramines, J. Pharm. Pharmacol., 2003, 5, 1021-1027. DOI: $10.1211 / 0022357021314$

13. Kettle, A. J.; Winterbourn, C. C., Assays for the chlorination activity of myeloperoxidase. Methods Enzymol. 1994, 233, 502- 512. DOI: 10.1016/S0076-6879(94)33056-5

14. Dypbukt, J. M.; Bishop, C.; Brooks, W. M.; Thong, B.; Eriksson, H.; Kettle, A. J., A sensitive and selective assay for chloramine production by myeloperoxidase, Free
Radical Biol. Med., 2005, 39, 1468-1477. DOI: 10.1016/j.freeradbiomed.2005.07.008

15. Boersma, B. J.; D’Alessandro, T.; Benton, M. R.; Kirk, M.; Wilson, L. S.; Prasain, J.; Botting, N. P.; Barnes, S.; Rley-Usmar, V. M.; Patel, R. P., Neutrophil myeloperoxidase chlorinates and nitrates soy isoflavones and enhances their antioxidant properties. Free Radical Biol. Med., 2003, 35, 1417-1430. DOI: 10.1016/j.freeradbiomed.2003.08.009

16. Ketsukinai, S.; Urano, Y.; Kakinuma, K.; Majima, H. J.; Nagano, T., Development of novel fluorescence probes that can reliably detect reactive oxygen species and distinguish specific species. J. Biol. Chem., 2003, 278, 3170-3175. DOI: 10.1074/jbc.M209264200

17. Teufelhofer, O.; Weiss, R. M.; Parzefall, W.; Schulte-Hermann, R.; Micksche, M. Berger, W.; Elbling, L., Promyelocytic HL60 cells express NADPH oxidase and are excellent targets in a rapid spectrophotometric microplate assay for extracellular superoxide. Toxicol. Sci., 2003, 76, 376383. DOI: $10.1093 /$ toxsci/kfg234

18. Wagner, B. A.; Buettner, G. R.; Oberley, L. W.; Darby, C. J.; Burns, P. C., Myeloperoxidase is involved in $\mathrm{H} 2 \mathrm{O} 2-$ induced apoptosis of HL-60 human leukemia cells, J. Biol. Chem., 2000, 275, 2246122469. DOI: $10.1074 / \mathrm{jbc} . \mathrm{M} 001434200$

19. Jiang, H.; Ju, H. X., Electrochemiluminescence sensors for scavengers of hydroxyl radical based on its annihilation in CdSe quantum dots film/peroxide system, Anal. Chem., 2007, 79, 6690-6696. DOI: 10.1021/ac071061j

20. Wang, S. H.; Han, M. Y.; Huang, D. J. Nitric oxide switches on the photoluminescence of molecularly engineered quantum dots, J. Am. Chem. Soc., 2009, 131, 11692-11694. DOI: $10.1021 / \mathrm{ja} 904824 \mathrm{w}$

21. Mancini, M. C.; Kairdolf, B. A.; Smith, A. M.; Nie, S., Oxidative quenching and degradation of polymer-encapsulated quantum dots: new insights into the longterm fate and toxicity of nanocrystals in vivo. J. Am. Chem. Soc., 2008, 130, 1083610837. DOI: $10.1021 /$ ja8040477 
22. Zhou, Y.; Chen, H.; Ogawa, N.; Lin, J-M. Chemiluminescence from $\mathrm{NaClO}-\mathrm{H} 2 \mathrm{O} 2$ and enhanced by L-cysteine capped Mn-doped $\mathrm{ZnS}$ quantum-dots, J. Luminescence, 2011, 131, 1991-1997.

DOI: 10.1016/j.jlumin.2011.04.019

23. Mancini, M. C.; Kairdolf, B. A.; Smith, A. M.; Nie, S. Oxidative Quenching and Degradation of Polymer-Encapsulated Quantum Dots: New Insights into the LongTerm Fate and Toxicity of Nanocrystals in Vivo J. Am. Chem. Soc., 2008, 130, 1083610838. DOI: 10.1021/ja8040477

24. Yan, Y.; Wang, S. H.; Liu, Z. W., Wang, H. Y.; Huang, D. J. CdSe-ZnS quantum dots for selective and sensitive detection and quantification of hypochlorite. Anal. Chem., 2010, 82, 9775-9781. DOI: 10.1021/ac $\underline{101929 \mathrm{q}}$

25. Cavallaro, A.; Ainis, T.; Bottari, C.; Fimiani, V., Effect of resveratrol on some activities of isolated and in whole blood human neutrophils, Physiol. Res., 2003, 52, 555562.

26. Kohnen, S.; Franck, T.; Van Antwerpen, P.; Zouaoui Boudjeltia, K.; Mouithys-Mickalad, A.; Deby, C.; Moguilevsky, N.; DebyDupont, G.; Lamy, M.; Serteyn, D. Resveratrol inhibits the activity of equine neutrophil myeloperoxidase by a direct interaction with the enzyme. J. Agric. Food Chem., 2007, 55, 8080-8087. DOI: 10.1021/jf071741n

27. Jerlich, A.; Fritz, G.; Kharrazi, H.; Hammel, M.; Tschabuschnig, S.; Glatter, O.; Schaur, R. J., Comparison of $\mathrm{HOCl}$ traps with myeloperoxidase inhibitors in prevention of low density lipoprotein oxidation, Biochim. Biophys. Acta, 2000, 1481, 109-118. DOI: 10.1016/S0617-4838(00)00112-6

28. Pattison, D. I.; Davies, M. J., Reactions of myeloperoxidase derived oxidants with biological substrates: gaining chemical insight into human inflammatory diseases, Curr. Med. Chem., 2006, 13, 3271-3290.

29. Winterbourn, C. C., Comparative reactivities of various biological compounds with myeloperoxidase-hydrogen peroxidechloride, and similarity of the oxidant to hypochlorite, Biochim. Biophys. Acta 1985, 840, 204-210. DOI: 10.1016/03044165(85)90120-5

30. Peskin, A. V.; Winterbourn, C. C. Kinetics of the reactions of hypochlorous acid and amino acid chloramines with thiols, methionine, and ascorbate, Free Radical Biol. Med. 2001, 30, 572-579. DOI: 10.1016/S0891-5849(00)00506-2

31. Maldonado, P. D.; Rivero-Cruz, I; Mata, R.; Pedraza-Chaverr, J., Antioxidant activity of A-type proanthocyanidins from Geranium niveum (Geraniaceae). J. Agric. Food Chem., 2005, 53, 1996-2001. DOI: 10.1021/jf0483725

32. Henderson, L. M.; Chappell, J. B., Dihydrorhodamine 123: a fluorescent probe for superoxide generation? Eur. J. Biochem., 1993, 217, 973-980.

33. Malle, E.; Furtmuller, P. G.; Sattler, W.; Obinger, C. Myeloperoxidase: a target for new drug development? Br. J. Pharmacol., 2007, 152, 838-854. DOI: 10.1038/sj.bjp.0707358

34. Myhre, O.; Andersen, J. M.; Aarnes, H.; Fonnum, F. Evaluation of the probes 2',7'dichlorofluorescin diacetate, luminol, and lucigenin as indicators of reactive species formation. Biochem. Pharmacol. 2003, 65, $1575-1582$. DOI: $10.1016 / \mathrm{S} 0006-$ 2952(03)00083-2 